\title{
Current advances in magnetic resonance imaging (MRI) in spinal cord trauma: review article
}

\author{
M Perovitch MD, ${ }^{1} \mathrm{~S}$ Perl MD, H Wang $\mathrm{MD}^{2}$ \\ The Johns Hopkins University Medical Institutions, Baltimore, and the MRI Laboratories, \\ Clinton, Maryland, USA.
}

\begin{abstract}
Magnetic resonance (MR) images of 87 patients who had sustained spinal cord injuries during the past 2 years, were analyzed and compared with the corresponding clinical, surgical, and in some cases pathological findings. In addition to the standard MR imaging techniques applied in the spinal cord injuries, we also introduced some recent MRI technical achievements which are anticipated to improve diagnostic accuracy and broaden clinical application of this modality with regard to the spinal cord trauma. The recent technical advancements that we used include image enhancement, fat tissue signal suppression, three-dimensional (3-D) imaging, and magnetic resonance angiography (MRA). The reviewed post traumatic changes disclosed in these MR images were classified in 4 categories: acute, subacute, chronic, and the injury's sequelae. The essential properties of the 4 new imaging advancements are considered in relationship to the gain in diagnostic improvement of MRI of the 4 phases of patients with spinal cord trauma.
\end{abstract}

Key words: spinal cord trauma; magnetic resonance imaging (MRI); new
techniques.

\section{Introduction}

Some well recognized characteristics of magnetic resonance imaging (MRI) of the spinal cord demonstrate that this diagnostic modality has certain advantages over other neuroimaging techniques. ${ }^{1-4}$ Among these advantages of significance for the evaluation of an injured spine and spinal cord are the excellent contrast resolution of MR images, the absence of bone artifacts, the feasibility of multiplanar imaging without changing the patient's position, and the choice of different pulse sequences which intensify the anatomical detail and contribute to MRI sensitivity $^{5-9}$ (Fig 1). Yet, it is also important to recognize the existing limitations that affect the diagnostic accuracy of MRI in spinal cord trauma. ${ }^{10}$ They include the rather long imaging time during which the patient is asked to remain motionless in the required position. Furthermore, the imaging may be impeded by certain supporting devices (traction, intubation, anesthesia equipment, etc), or it may turn out unpro-

Correspondence: 48 High Farms Rd, West Hartford, CT 06107, USA. ductive. In addition, MRI cannot always provide the diagnosis of the type of lesion, and the separation of the basic lesion from perifocal edema is, at best, difficult with MR images. ${ }^{11-13}$ Also, MRI does not offer in all cases information about necrotic or calcified areas or vascular anomalies related to the injury, and, on occasion, the sensitivity of MRI is suboptimal, thus the presence of a traumatic lesion of the spinal cord can remain uncertain. ${ }^{14,15}$ But despite these insufficiencies, one can say that MRI is the best neuroimaging technique for the evaluation of spinal cord injury that we have at present. It is superior to high resolution computed tomography (CT) or delayed metrizamide CT, and as accurate as intraoperative sonography. ${ }^{16}$ However, MRI can be performed as many times as necessary, even on an outpatient basis, without known hazards or major discomfort to patients, which is not the case with intraoperative sonography.

Since its introduction into clinical practice, MRI has been continuously undergoing technical improvements, which have step by step brought its diagnostic accuracy to a 


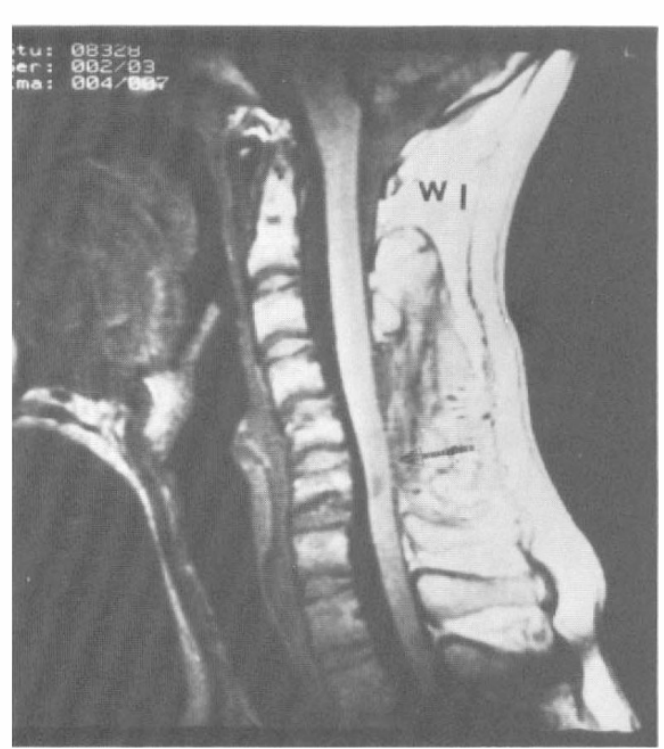

Figure 1 The saggital MR image shows a deformity of the C5-C6 vertebrae, and a large defect of the posterior cervical wall at the myelotomy site. There is a cylindrically shaped lesion of low signal intensity, indicated by the arrow, in the cervical spinal cord substance, representing a post traumatic cyst. The outstanding contrast seen in this image is one of the main features of MRI.

high level. Among recent technical advancements, 4 are important in our view for the evaluation of patients with spinal cord injuries: namely, image enhancement, signal suppression, three-dimensional (3-D) imaging and magnetic resonance angiograghy (MRA).

We would like to describe the main features of the above mentioned $4 \mathrm{MR}$ imaging advancements without entering into detailed analysis of their physical properties, which is not the purpose of this paper. Also, we wish to correlate, within the amount of space allocated to us, MRI findings obtained by means of these advances, with the pathological picture of a spinal cord injury in the acute, subacute, chronic and final (sequelae) phases.

In summary, the pathological findings of acute blunt injury to the spinal cord point to the occurrence of hemorrhage and edema within the central cord mostly at the level of impact. The disruption of the vascular network results in the impairment of blood flow, petechial hemorrhages, and alteration of the blood-brain barrier. If the dura is lacerated the swollen spinal cord can extrude through the defect. In addition, a nerve root avulsion or fracture of the bony elements or discs can be present as well as epidural hematoma. In general the severity of the trauma will depend upon the area of impact, velocity, mass, and whether the spinal column was fixed or movable at the moment of injury. Penetrating injuries (caused by bullets, knives, flying glass, metal or bony fragments, etc) range from small lesions to hemisection or transection of the spinal cord, and the amount of hemorrhage will depend upon the extent of damage to blood vessels. Fractures of the bony components of the spine and discs, laceration of the meninges, and damage to the nerve roots are commonly encountered. Both types of injuries in the subacute phase lead to central necrosis which appears within hours to days, and degeneration of the white matter tracts which continues over a period of weeks. In the later phases changes which tend to become permanent take place such as cavities in the spinal cord, from single to multiple, resulting in post traumatic syringomyelia, and gliosis localized or diffuse, and also atrophy, adhesions, osteomyelitis and occasionally abscess formation, thrombosis of the feeding arteries, post traumatic arterio-venous shunts, etc. ${ }^{17}$

For the past 2 years we have analyzed the appearances of pathological changes in post traumatic MR images of 87 patients, and have assessed the effects of the new imaging techniques now available.

\section{Methods}

\section{Paramagnetic enhancers}

The first paramagnetic enhancer used in clinical practice (since June 1988, in the USA) is gadolinium diethylenetriaminopenta-acetic acid (Gd-DTPA). Later, other pharmaceutical compounds of gadolinium have been introduced, for example gadopentetate dimeglumine, which we have been using commonly so far. Apart from gadolinium there are quite a number of other substances that have an MR enhancing ability, and we should expect in the future 
the introduction of various MRI enhancers, in particular for MRA.

The paramagnetic substances differ in their nature from iodinated contrast media which provide image contrast by direct action. An increase in concentration of the contrast medium causes an increase in the image contrast. Conversely, the paramagnetic substances have the ability to enhance the relaxation process of adjacent protons. This enhancement results from the interaction of protons with unpaired electrons of the paramagnetic substance. In this process the paramagnetic enhancer itself is not imaged. ${ }^{18,19}$ Consequently, paramagnetic enhancers have an indirect effect on the image contrast. It should be noted that in high concentrations the action of paramagnetic enhancers may be minimal or reversed, a phenomenon known as 'negative enhancement'.

Gadolinium proved to be very suitable for clinical studies because of its marked effect on proton relaxation, its stability, rapid renal clearance, and its good tolerance by patients. Yet, it can cause a transient increase in serum iron concentration, which is observed in about $20-30 \%$ of patients, as well as a rise in serum bilirubin, though in a smaller number of patients. Both changes were of short duration without noticeable clinical sequelae. The presently used dose is 0.1 to $0.2 \mathrm{mmol} / \mathrm{kg}$, although we obtained satisfactory enhancement even with a dose of $0.05 \mathrm{mmol} / \mathrm{kg}$.

Two biological properties of Gd-DTPA should also be mentioned. The distribution of Gd-DTPA is extracellular, and under normal conditions it does not cross the blood-brain barrier, a phenomenon that should be considered in the process of analyzing post traumatic MR images of the spinal cord. For further information concerning the biological effects of gadolinium, we wish to refer the reader to some research work which elucidates this matter in a more detailed way. ${ }^{20-24}$

The application of $\mathrm{Gd}$ will usually enhance the image of an acute intramedullary hematoma. Subacute hematomas appear mostly intense with or without Gd enhancement, and a dark halo may be seen in the periphery of a chronic hematoma (Fig 2).

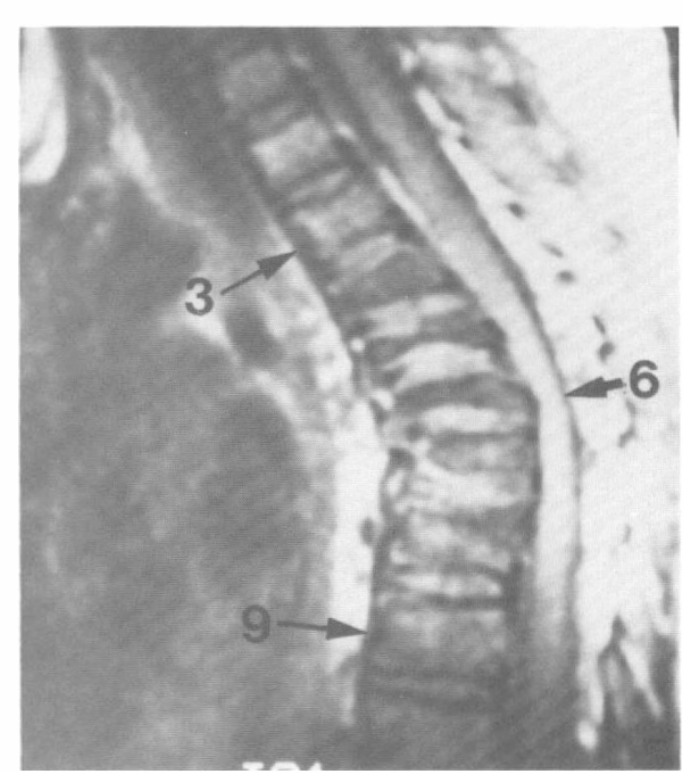

Figure 2 Two hours following injury in a motor vehicle accident (MVA) this sagittal image of the thoracic spine was obtained with Gd enhancement. The patient developed paraplegia immediately after the accident. The image demonstrates fractures of T5-T6-T7 and also T3 and T9. Kyphotic deformity in the mid thoracic spine is compromising the spinal canal and impinging on the cord. The hyperintensity in the spinal cord at the level of compression (arrow at 6) indicates the presence of enhanced hemorrhage. There is considerable swelling of the cord above and below the T6-T7 area, with a visible expansion of hemorrhage.

Furthermore, acute post traumatic spinal cord contusion becomes more evident if $\mathrm{Gd}$ is used. The presence of blood can be associated with myelomalacia, and in this situation Gd may be helpful in dissociating the 2 lesions (Fig 3). Furthermore, the Gd enhancement provides, in most instances, additional information about the presence and expansion of an epidural hematoma and its relationship to the spinal cord (Fig 4). The enhancement with Gd of the sequelae of spinal cord injuries may prove to be rewarding by making cavities or gliosis more distinct in post traumatic multiloculated syringomyelia (Fig 5), or the presence of a single cavity. The enhancement of epidural scars and of localized or diffuse meningeal adhesions is mostly of an informative 


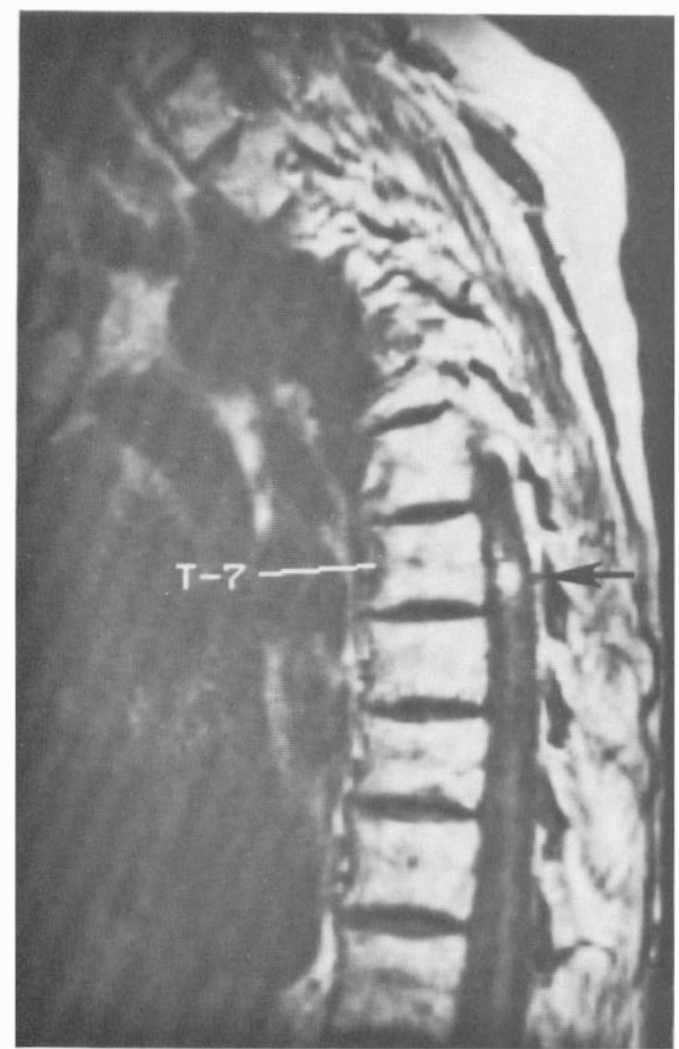

Figure 3 After a stable clinical period, following a thoracic spinal injury in a motor vehicle accident (MVA), the patient developed paraparesis of the lower extremities. The sagittal MR image with Gd enhancement depicts at the level of the $\mathrm{T} 7$ vertebral body a focal lesion with the characteristics of an old blood accumulation encircled by a poorly defined clear zone representing myelomalacia (arrow).

nature. ${ }^{25}$ The differentiation between the spinal nerve root sheath and scars is more reliable in $\mathrm{Gd}$ enhanced than in unenhanced MR images. ${ }^{26}$

On the basis of our present experience with the application of gadolinium compounds in spinal cord injuries, we think that in order to obtain the maximal benefit from enhancement patients should be very carefully selected. We do not apply gadolinium systemically, but prefer first to consider the use of appropriate pulse sequences and suppression techniques. ${ }^{12,25-30}$

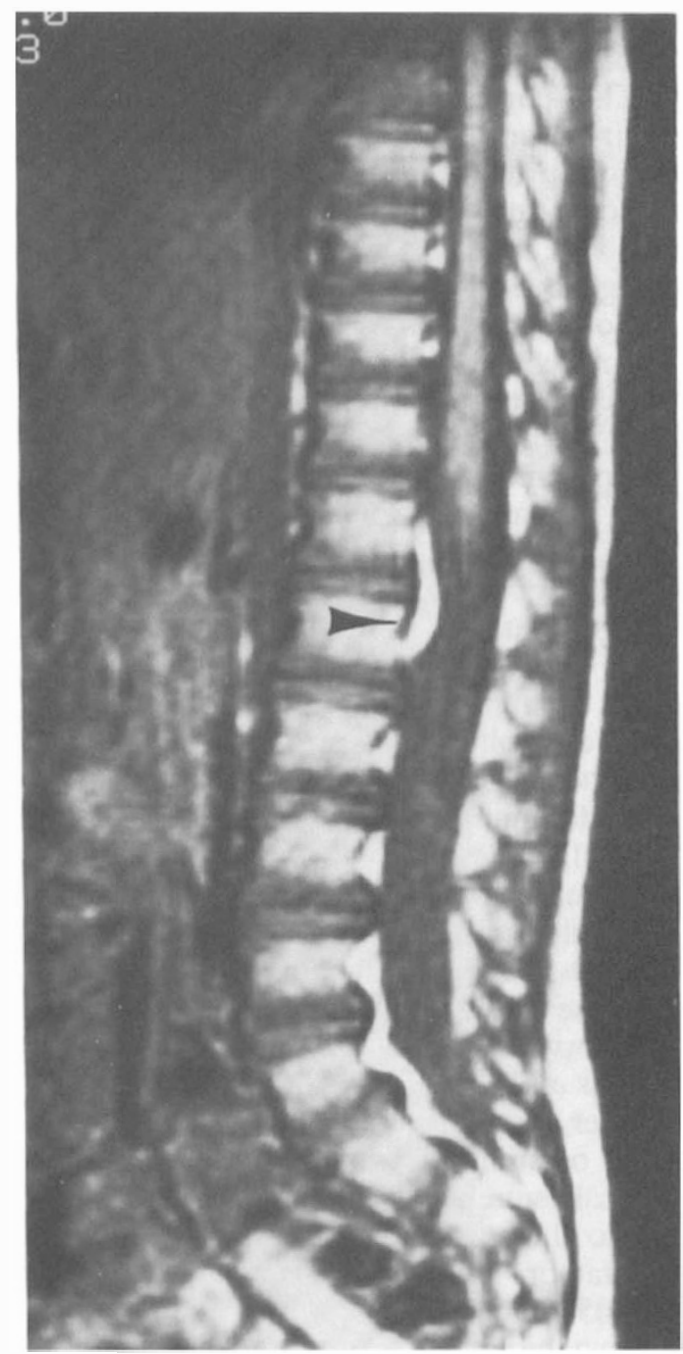

Figure 4 At the T12-L1 level (arrow) in this T-1 enhanced sagittal MR image of the thoracolumbar spine, an epidural hematoma is clearly outlined. The hematoma is compressing the ventral thecal sac. There is some faint appearance of $\mathrm{Gd}$ in the conus indicating the possibility of a contusion. The patient sustained an injury of the spine in a MVA.

\section{Signal suppression}

The presence of fat tissue in and outwith the spinal canal can interfere with image enhancement. That is, signals originating from fat tissue can cause a similar contrast intensity as a gadolinium enhanced lesion. Hence, both tissues will appear isointense in 


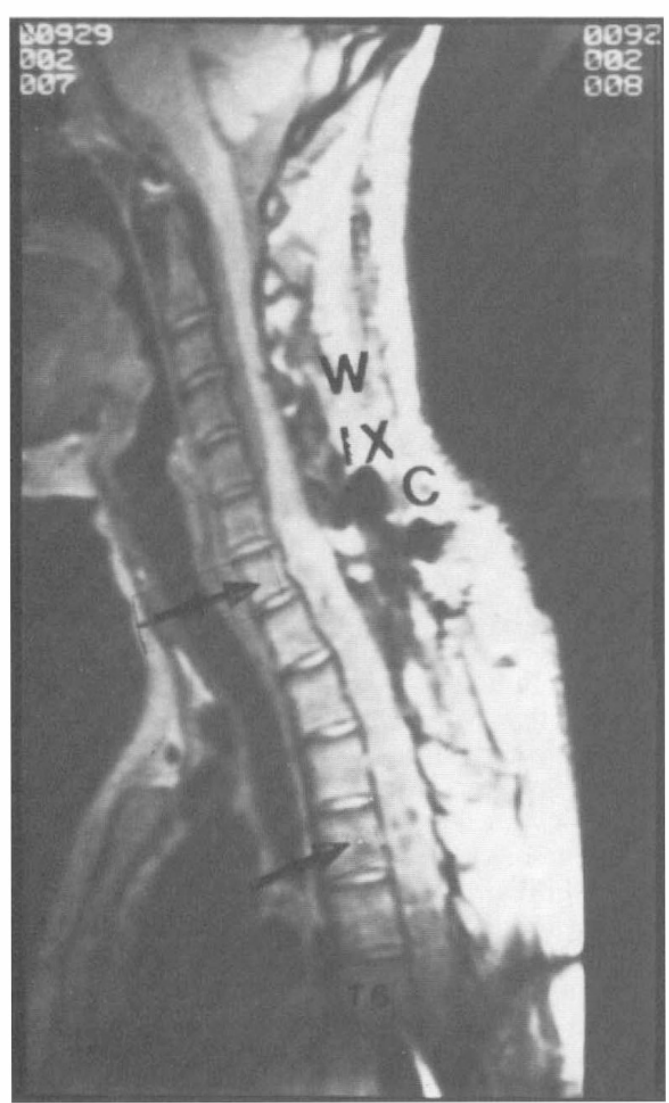

Figure 5 This sagittal Gd enhanced MR image of the cervical and upper thoracic spine of a patient who had a severe injury and required surgical treatment about 2 years ago, depicts atrophy of the spinal cord from the cerivcomedullary junction to the level of the C5 vertebra. From that level the spinal cord is noticeably dilated to the sixth thoracic vertebra. The subdural space is virtually obliterated by the expanded cord in the substance of which one can see a cavity with multiple separations, characteristic of multiloculated syringomyelia (arrows). At the level of C6 there is an increase of signal intensity consistent with enhanced gliosis (upper arrow). The postoperative defect of the posterior cervical wall is well defined.

the images, and the differentiation of the lesion in the spinal cord from fatty tissue will be difficult, if not impossible. To overcome this problem in the imaging of patients with spinal cord injuries, it may be rewarding to apply the fat suppression sequences with or without gadolinium enhancement. Such a fat suppression technique is expected to produce a selective reduction of the fat tissue signal intensity, without affecting the signal intensity of post traumatic lesions of the spinal cord. In fact, by using fat suppressing techniques, the characterization and delineation of a lesion should be improved.

There are different fat suppression techniques introduced for MR imaging which can be applied to the investigation of the injured spine and cord. Fat suppression can be accomplished with a frequency-selective presaturation pulse, ${ }^{31}$ or with a hybrid technique used for solvent suppression in proton spectroscopy with the chopper fat suppression sequence. ${ }^{32,33}$ The chopper fat suppression technique can be regarded as a real-time Dixon technique. ${ }^{34}$

An effective and relatively simple method of fat suppression is the hybrid sequence that does not require an increase in acquisition time. It does require, however, the adjustment of some parameters. Improper adjustment of these parameters may impede the process of fat suppression. The optimal fat suppression with the chopper sequence depends upon a good static field homogeneity, and represents a more complex procedure. In summary, by reducing the chemical-shift misregistration artifact the fat suppression sequence can increase the contrast between the fat tissue and high signal intensity lesions such as a subacute hemorrhage in the injured spinal cord. ${ }^{35-37}$

We have achieved good results in the evaluation of spinal cord injuries. For example, we have been able to delineate clearly, even without gadolinium, the presence of spinal cord contusion, hemorrhage, or compression by fractured vertebrae (Fig 6). The relationship between the spinal cord and extruded fragments of ruptured discs or injured vertebrae was obvious (Fig 7). Also, the damage caused to spinal nerve roots and the presence of epidural bleeding could be recognized by applying the fat suppression method (Fig 8). The imaging of post traumatic gliosis, scars and fibrotic changes associated with the surgical treatment of an injured spine and cord, with or without gadolinium, was informative in fat suppression MR images (Fig 9). 


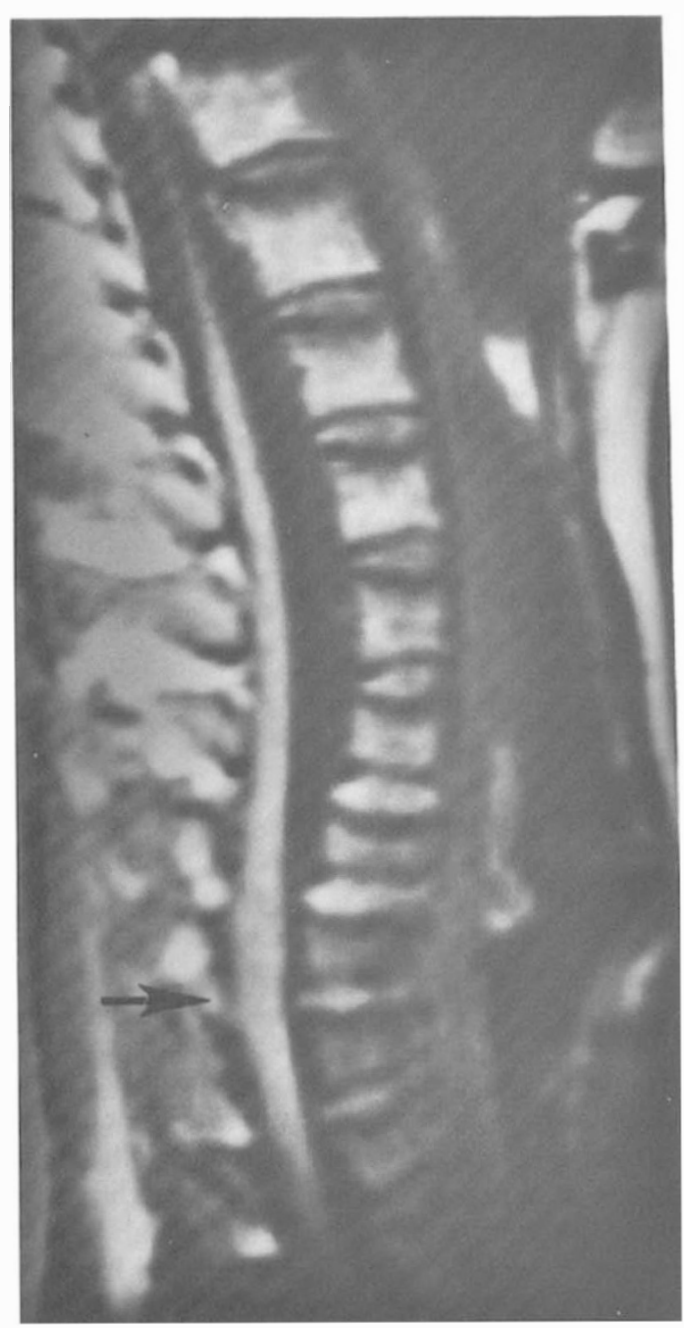

Figure 6 The sagittal T-1 MR image of the cervical and upper thoracic spine obtained with the fat suppression technique. The image is from a 12 year old male who had a severe fall, causing a hyperflexion injury of the neck. Swelling of the spinal cord from C3 to C5 (arrow) is clearly outlined and is compatible with cord contusion. In addition, the fracture of the $\mathrm{C} 5$ vertebra is evident. No gadolinium enhancement was applied.

Although the experience with fat suppression methods is, at this time of writing, relatively limited, it is our impression that its implementation in the process of the evaluation of spinal cord injuries has its merit. It provides informative images of a traumatized spinal cord without the neces-

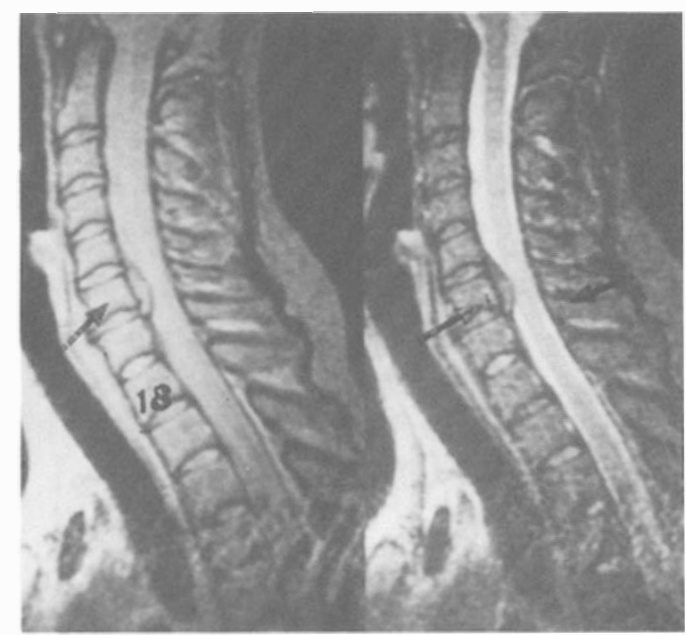

Figure 7 Following a motor vehicle accident (MVA) this MRI was performed with the fat suppression technique in a female patient. A post traumatic herniated nucleus pulposus at the C6-7 level is clearly outlined with a large fragment of disc which has migrated superiorly and overlies the body of C6. The cervical cord at that level is compressed to a transverse diameter of approximately $6 \mathrm{~mm}$. At the site of the compression there is an increase in signal indicating the presence of spinal cord contusion. No gadolinium enhancement.

sity of the injection of gadolinium in many instances, which may facilitate the examination of paraplegic or quadriplegic patients, especially in view of the fact that these patients often require multiple follow up imaging examinations. However, as we indicated earlier, further improvements on fat suppression techniques are needed to upgrade and broaden the clinical application of this diagnostic modality with regard to spinal cord injuries. ${ }^{38,39}$

\section{Three-dimensional MRI}

Not long ago the possibility of three-dimensional (3-D) or volume-acquired imaging became available, representing a major advancement in MR technology. In the near future it may supersede the presently used two-dimensional (2-D) display of anatomical structures of the spine, which in reality has 3 dimensions.

The essential difference between the 2 

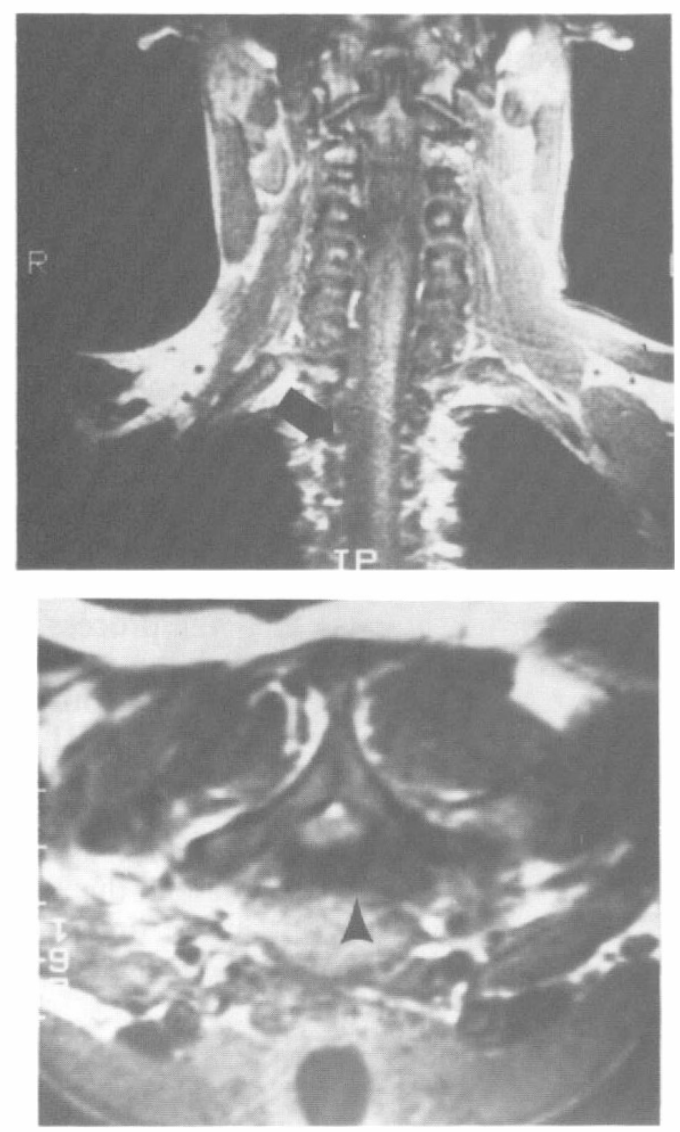

Figure 8 MR images of the thorax and cervical area obtained with the fat suppression method without enhancement, of a 15 year old male with the history of a motor vehicle accident (MVA). On admittance to hospital he complained of right upper extremity weakness. The coronal and axial images show a widening of the subarachnoid space (arrows) on the right side, approximately from C6 to T3 level. There is clear evidence of compression and displacement of the cord to the left side. These findings were compatible with avulsion and effusion of cerebrospinal fluid. At surgery, apart from the cerebrospinal fluid leakage related to the nerve avulsion, a larger amount of blood was also found, resulting from the laceration of a small artery.

imaging methods is that the 3-D technique has the capability to collect MRI data from the entire volume of the region rather than from a single scan at a time, as is the case with 2-D imaging. Furthermore, the data

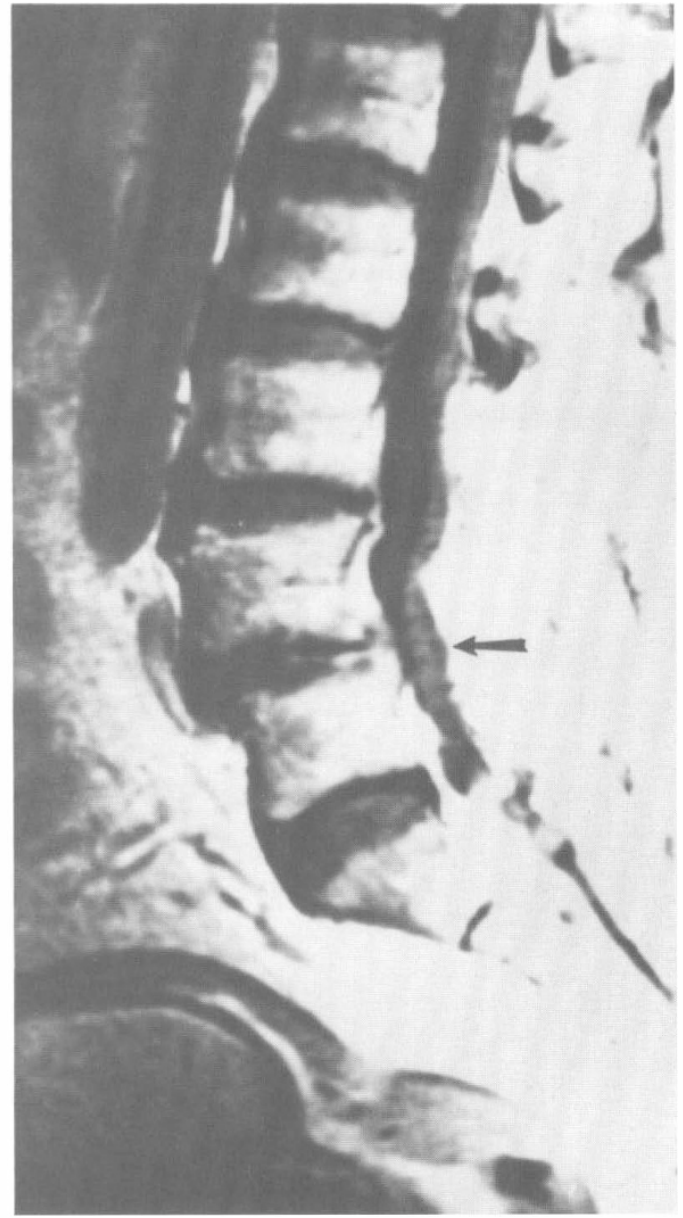

Figure 9 The MR image in sagittal projection, enhanced with gadolinium and the fat suppression method, of a female patient who was injured 2 years ago in a MVA. She had several fractures of the lumbar vertebrae, and had 2 post traumatic laminectomies. Her main complaints at the time of this examination were pain and weakness of the lower extremities. The MRI disclosed stenosis of the lumbar spinal canal with thick layers of scar tissue covering the dorsal wall of the spinal canal and expanding into the thoracic area (arrow).

obtained can be reformatted so that one can see any part of the examined area from any angle. Using the 2-D method each image of a different plane must be reconstructed from a single scan. It is expected that the 3-D MRI will provide high resolution pictures of the pathological process in all 
dimensions from a single acquisition, which means that the present long MRI time will be greatly shortened, thus eliminating a major disadvantage of MRI imaging. ${ }^{40}$ These features of 3-D imaging are of special interest for the evaluation of spinal cord injuries.

It should be mentioned that the 3-D imaging modality is not new and has been used for research purposes for a long period of time, but much experimental work was necessary to combine the fast gradient-echo sequences, advances in computer processing, and high magnetic field strength in order to bring 3-D imaging into clinical practice.

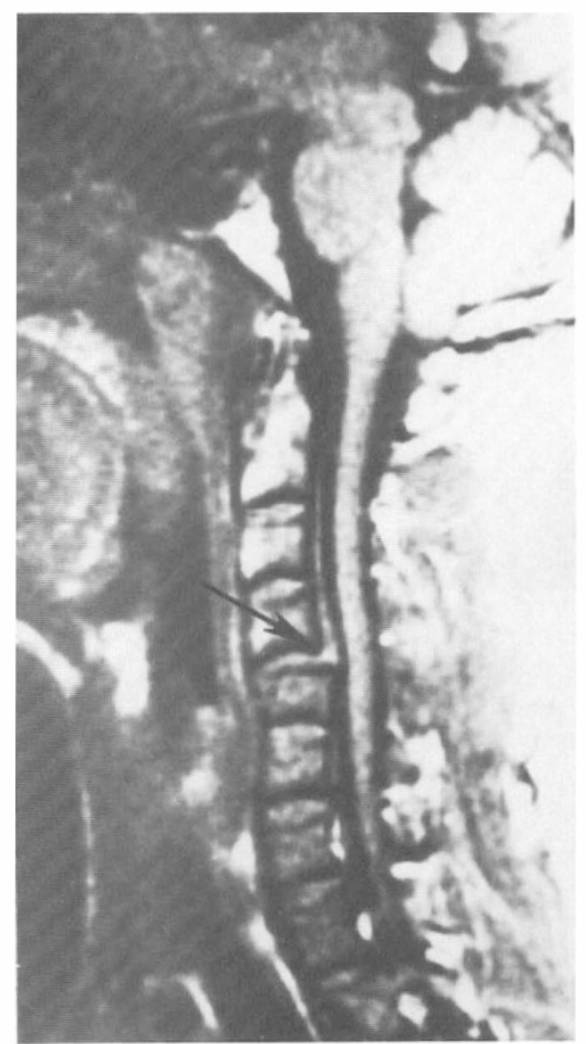

Figure 10a Following a MVA: subluxation of the cervical spine on admittance to hospital. The sagittal $\mathrm{Tl}$ image of the cervical spine reveals a disc fracture with extrusion of fragments at the C4-C5 level and dislocation of these vertebrae. An extensive epidural hemorrhage elevating the posterior longitudinal ligament is evident (arrow). The spinal cord appears to be displaced towards the dorsal wall.
In 3-D FLASH gradient-echo sequences the contrast in T-1 appears to be superior to the one provided by $2-\mathrm{D}$ spin-echo techniques. The improved $\mathrm{T}-1$ contrast of the 3-D FLASH system also increases the enhancing effect of Gd-DTPA. ${ }^{41}$

The present research in the area of 3-D technology is also focused on the possibility of combining in a clinical setting the 3-D brain display with functional data obtained from positron emission tomography scans. ${ }^{42}$

The main region most extensively investigated at present with 3-D techniques is the central nervous system. Our first experiences with the application of this imaging modality in trauma of the spine and spinal cord are promising. The imaging process is faster and the data displayed in the images are more abundant and informative. Both of these qualities are significant when MRI is carried out on a paraplegic or quadriplegic patient, especially soon after the spinal injury. The images presented here, as an example, support this opinion about the 3-D method (Fig 10). However, more time will be needed to evaluate fully the diagnostic advantages of 3-D MRI. ${ }^{43}$

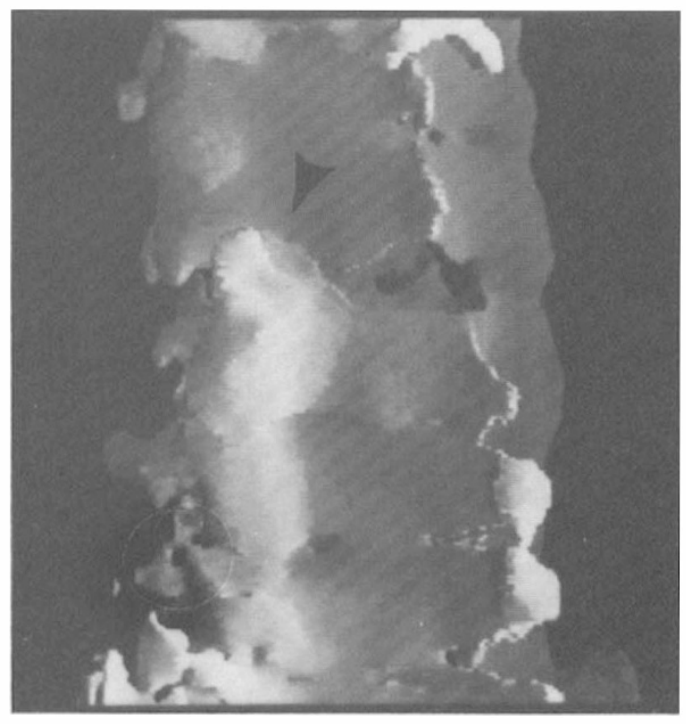

b A 3-D image in the posterior oblique view: the left inferior facet of $\mathrm{C} 4$ has jumped anteriorly (arrow) leaving the superior facet of C5 bare (arrow). The widening of the interspinous distance and rotation of the spine at that level are also depicted. 


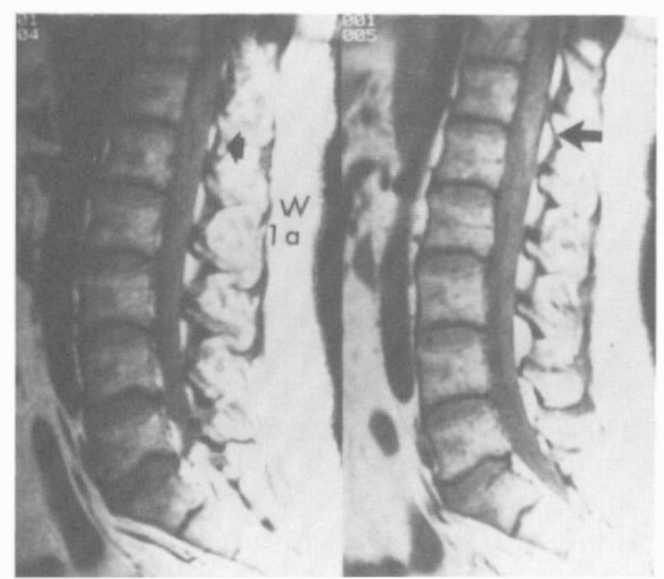

Figure 11a A saggital MR image of a 42 year old male with a severe progressive weakness of the lower extremities, shows a lesion in the area of the conus (arrow).

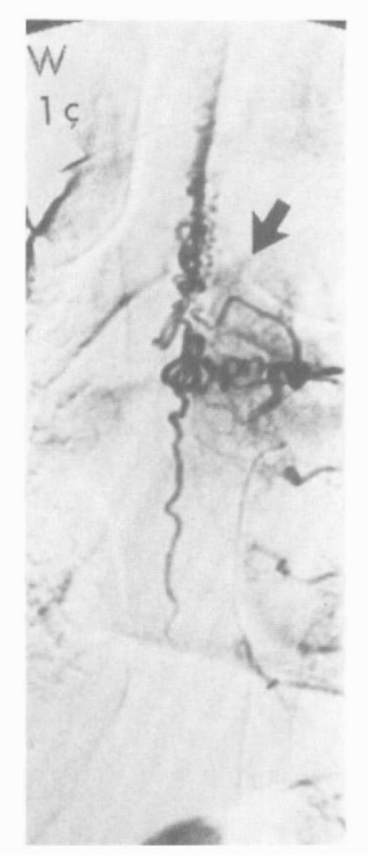

$M R$ angiography (MRA)

Spinal cord injuries are commonly associated with more or less severe disturbances of blood flow, often caused by lacerations, thrombosis or embolization of the cord's feeding arteries. In the later phase, arteriovenous shunts or anomalies of the venous system may occur. Thus, it is important for

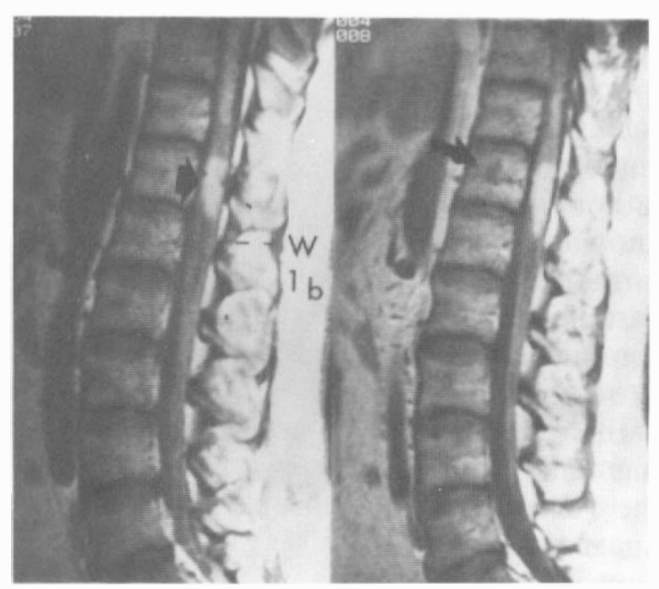

b Following the application of gadolinium the lesion appears bright (arrow). The diffusion of gadolinium is seen above and below the lesion indicating the possibility of enlarged cord's blood vessels.

c Angiography disclosed an extensive arteriovenous shunt (arrow). At surgery an arteriovenous malformation was found at the level of T12. The patient had a severe injury of the spine in a MVA about two years ago.

clinical assessment and the planning of treatment to have an accurate knowledge about the magnitude of the damage caused to the spinal cord and its blood supply by trauma to the spine. This may be especially true for some patients in which MRI techniques disclose a minor involvement of the cord substance in contrast to the severity of 


\section{Perovitch et al}

the clinical signs caused by an obstruction to blood flow. ${ }^{44}$ So far, the evaluation of the spinal cord vascular network has been achieved by means of selective spinal cord angiography. However, this procedure is rather complex and there may be some well known complications. ${ }^{45}$ Hence, the performance of selective angiography in a paraplegic or quadriplegic patient is at best complicated and it may also aggravate the existing condition. ${ }^{46}$

In MR images one can incidentally see segments of an artery or vein belonging to the vascular system of the spinal cord. In images with enhancement these vessels may appear more prominent if arterio-venous shunt or venous thrombosis are present. ${ }^{47}$ But apart from the latter situations, the MRI of the spinal cord blood supply has so far been unsuccessful due to different technical obstacles such as vessel size and tortuosity, the unpredictable nature of the blood flow, and turbulence. Furthermore, the resolution obtained with MR has been 2 to 5 times inferior to that obtained by conventional or digital subtraction selective spinal cord angiography (Fig 11).

Nevertheless, the recently attained improvements of MR angiographic technology have brought this diagnostic modality closer to clinical utility. The new imaging methods tested, including cardiac-gated spin-echo, gradient-echo, out-of-field saturation-pulse sequences, have improved the image quality. Successful tests were also achieved by using 3-D MRA. Moreover, clinically usable data about the state of both carotid arteries were demonstrated in 3-D FLASH sequences. The application of gadolinium compounds have, in addition, further improved the blood flow signal and consequently also the image quality. ${ }^{48}$

The clinical application of MRA for the evaluation of the extra and intracranial blood flow has notably increased in the course of the past year. ${ }^{49-51}$ However, our experiences with MRA of spinal cord lesions are rather limited, especially concerning traumatic lesions. ${ }^{52}$ As further refinements of MRA technology are expected, its broader use in the evaluation of spinal cord trauma is only a question of time. The properties of MRA are most suitable for the imaging of the spinal blood flow, with or without enhancement, in particular with regard to its safety, the possibility to repeat the study, and the fact that there is little discomfort to the patient.

\section{Conclusion}

This brief description of 4 new MR techniques represents a review of some diagnostic modalities that are expected to broaden the clinical application of MR in the evaluation of spinal cord trauma and improve its accuracy. We omitted to elaborate upon the physical properties of the $4 \mathrm{MR}$ advancements because this was not the purpose of our communication. In the references, however, a number of excellent studies dealing with this matter are mentioned.

\section{References}

1 Bradley WGF, Walush V, Valley RA, Wycoff RR (1984) Comparison of CT and MR in 400 patients with suspected disease of the brain and cervical spinal cord. Radiology 152: 695-702.

2 Edelstein WA, Bottomley PA, Hart HR, Smith LS (1983) Signal noise and contrast in nuclear magnetic resonance imaging. J Comput Assist Tomogr 7: 391-401.

3 Kneela'd JB, Knowles RJR, Cahill PT (1984) Magnetic resonance imaging systems: optimization in clinical use. Radiology 153: 473-478.

4 Perovitch M (1984) Potential application of NMR in brain disorders. In: Proceedings Annual Meeting American Association for Advancement of Science. AAAS Publications, Washington DC: 177.

5 Brasch RC (1983) Methods of contrast enhancement of NMR imaging and potential application. Radiology 147: $781-788$.

6 Hendrick RE, Newman FD, Hendee WR (1985) MR imaging technology maximizing the signal-to-noise ratio from a signal tissue. Radiology 156: 749-752.

7 Mills CM, Crooks LE, Kaufman L, Brant-Zawadzki M (1984) Cerebral abnormalities: use of calculated T1 and T2 magnetic resonance images for diagnosis. Radiology 150: 87-94.

8 Wehrli FW, MacFall JR, Shutts D, Bregr R, Nerfkens RJ (1984) Mechanisms of contrast in NMR imaging. J Comput Assist Tomogr 8: 369-380. 
9 Perovitch M (1985) Neuroradiological evaluation of headache. In: Pfaffenrath V, Lundberg P-O, Sajaanstad 0, editors. Updating in Headache. Springer-Verlag, Berlin, Heidelberg, New York: 76.

10 Perovitch M (1985) Assessment of recent neurological imaging modalities. Thirteenth World Congress of Neurology. Springer International Hamburg: 232(Suppl) 1-306: 5.

11 Perovitch M (1986) Assessment of the demyelinating and post-traumatic processes of the spinal cord by means of MR. In: Proceedings Tenth International Congress of Neuropathology. Convention Bureau, Stockholm: 373.

12 Perovitch M (1987) Advancements in the neuroimaging of the spinal cord. Paraplegia 25: 244-249.

13 Chakers WD, Flickinger F, Bresnahan CJ, Beattie MS, Weiss KL, Miller C, Stokes B (1987) MR imaging of the acute spinal cord trauma. AJNR 8: 5-10.

14 Perovitch M (1987) The application of magnetic resonance in spinal cord disorders. Paraplegia 25: $373-380$.

15 Czervionke FL, Daniels LD, Ho SPP, Yu S, Pech P, Strandt JA, Williams AL, Haughton VM (1988) The MR appearance of gray and white matter in the cervical spine. AJNR 9: 557-562.

16 Quencer RM, Sheldon JJ, Donovan-Post MJ, Diaz RD, Montalvo DM, Green BA, Eismont FJ (1986) Magnetic resonance imaging of the chronically injured cervical spinal cord. AJNR 7: 457-464.

17 Perovitch M (1981) Injuries to the spinal cord and meninges. In: Perovitch M, editor. Radiological Evaluation of the Spinal Cord, Vol. I. CRC Press, Boca Raton: 143.

18 Perovitch M (1986) The role of 'contrast media' in MR imaging. In: Reisner T, Binder H, Deisenhammer E, editors. Advances in Neuroimaging. Verlag der Wiener Medizinische Akademie, Wien: 356.

19 Weinmann HJ, Brasch RC, Press WR, Wesbey GE (1984) Characteristics of gadolinium-DTPA complex. AJR 142: 619-624.

20 Strich G, Hagan PL, Gerber KH, Slutsky RA (1985) Tissue distribution and magnetic resonance spin lattice relaxation. Effects of gadolinium-DTPA. Radiology 154: 723-726.

21 Boudreau RJ, Burbridge S, Sin S, Lohen MK (1987) Comparison of the biodistribution of manganese-54 DTPA and gadolinium-153 DTPA in dogs. J Nucl Med 28: 349-353.

22 Renkin EM (1978) Transport pathways through capillary endothelium. Microvasc Res 15: 123-136.

23 Valk J (1988) Gd-DTPA in MR of spinal lesions. AJNR 9: 345-350.

24 Perovitch M, Rosenbaum AE, Wener L (1989) The application of MRI in some intra and extramedullary disorders. In: Gerstenbrand F, Aichner F, editors. Neuroimaging II. Gustav Fisher Stuttgart-New York: 195.

25 Ross SJ, Dalamarter R, Hueftle MG, Masaryk TJ, Alkawa M, Carter J, VanDyke C, Modic MT (1989) Gadolinium-DTPA-enhanced MR imaging of the postoperative lumbar spine. AJNR 10: 37-46.

26 Breger KR, Williams LA, Daniels LD, Czervionke LF, Leighton PM, Houghton VM, Papke RA, Coffer M (1989) Contrast enhancement in spinal MR imaging. AJNR 10: 633-637.

27 Takahashi M, Sakamoto Y, Miyawaki M, Bussaka H (1987) Increased MR signal intensity secondary to chronic cervical cord compression. Neuroradiology 29: 550-556.

28 Sze G, Abramson A, Krol G, Liu D, Amster J, Zimmerman RD, Deck MDF (1988) Gadolinium-DTPA in the evaluation of intradural extramedullary spinal disease. AJNR 9: 153-163

29 Sze G, Krol G, Zimmerman DR, Deck DMF (1988) Intramedullary disease of the spine: diagnosis using gadolinium-DTPA-enhanced MR imaging. AJNR 9: 847-858.

30 Perovitch M (1988) Magnetic resonance imaging of the chronic post-traumatic spinal cord changes. In: Proceedings Twenty-seventh Annual Scientific Meeting of the International Medical Society of Paraplegia, Perth: 29

31 Rosen BR, Wedeen VJ, Brady TJ (1984) Selective saturation NMR imaging. J Comput Assist Tomogr 8: 813-818.

32 Hore PJ (1983) Solvent suppression in fourier transform nuclear magnetic resonance. J Magn Reson 55: 283-300.

33 Szumowski J, Plewes DB (1987) Separation of lipid and water MR imaging signals by chopper averaging in the time domain. Radiology 165: 247-250.

34 Dixon WT (1984) Simple proton spectroscopic imaging. Radiology 153: 189-194.

35 Frahm J, Haase A, Hanicke W, Matthael D, Bomsdorf H, Helzel T (1985) Chemical shift selective MR imaging using a whole-body magnet. Radiology 156: 441-444.

36 Daniels DL, Kneeland JB, Shimakawa AJ, Williams AL, Syvertsen A, Gager WE, Harris GJ (1986) MR imaging of the optic nerve and sheath: correcting for the chemical shift misregistration effect. AJNR 7: 249-253.

37 Simon J, Szumowski J, Totterman S, Plewes DB (1988) Fat-suppression MR imaging of the orbit. AJRN 9: 961-968.

38 Perovitch M, Wang H, Perl S (1990) La pathologie des nerfs craniens dans les images de la resonance magnetique, Part I (Abstr). Combined Meeting of the Swiss Societies of Neurology and Neurosurgery, Locarno. In preparation for the press.

39 Lloyd P, Hendrix J, Kneeland VM, Daniels DL, Szumowski J, Williams AL, Leighton PM, Czervionke LF (1990) MR imaging of optic nerve lesions: value of gadopentate dimeglumine and fat-suppression technique. AJNR 11: 749-754.

40 Lang P, Genant HK, Steiger P, Stoller DW, Young IR (1989) 3-D reformatting asserts clinical potential in MRI. Diagn Imaging 11: 80-84. 
41 Froelich JW, Field SA (1988) High-speed MR imaging ready for routine use. Diagn Imaging 10: $240-252$.

42 Marrett S, Evans AC, Collins I, Peters IM (1988) Three-dimensional MR-PET imaging in the human brain. Radiology (suppl): 169-369.

43 Perovitch M, Bryan RN, Glickson JD, Perl S, Kumar AJ, Wang H (1989) Advancements in the MR imaging and spectroscopy of the central nervous system neoplasms. Invited paper. Fourteenth World Congress of Neurology, New Delhi 1989. Neurology of India (Abstr) 37(Supp1): 8. In préss: Elsevier Science Publishers, Amsterdam.

44 Perovitch, M (1981) Spinal cord angiography: trauma of the spinal cord. In: Perovitch M, editor. Radiological Evaluation of the Spinal Cord, Vol. II. CRC Press, Boca Raton, Florida: 84.

45 Perovitch M (1981) Spinal cord angiography. In: Perovitch M, editor. Radiological Evaluation of the Spinal Cord, Vol. II. CRC Press, Boca Raton, Florida: 67.

46 Perovitch M (1983) Neuroradiology of the sequelae of the spinal cord trauma. In: Adams JH, editor. Trauma and regeneration. Acta Neurochirurgica, Suppl 32. Springer Verlag, New York and Wien: 91.

47 Dormont D, Gelberg F, Assouline E, Reizine D, Hellas A, Riche MC, Chiras J, Bories J, Merland JJ (1988) MR imaging of spinal cord arteriovenous malformations at $0.5 \mathrm{~T}$ : study of 34 cases. AJNR 9: 833-838.

48 Egerter DE (1989) Clinical studies raise hopes for routine MR angiography. Diagn Imaging 11: $113-129$.

49 Bradley A, Jabour MD (1990) MRI assists in workup of cerebral aneurysms. Diagn Imaging November: $148-153$.

50 Egerter DE (1991) X-ray angio declines as MRA use expands. Diagn Imaging February: 131-142.

51 Edelman RR (1991) Advances roll back limitations of MRA. Diagn Imaging February: 119-127.

52 Perovitch M, Bryan RN, Glickson JD, Kumar AJ, Perl S, Ottesen O, Wang H (1990) Evaluation of CNS tumors by means of new MRI techniques. In: Proceedings Eleventh International Congress of Neuropathology, Kyoto: 277. In press: Jap J Neuropathol (Suppl). 